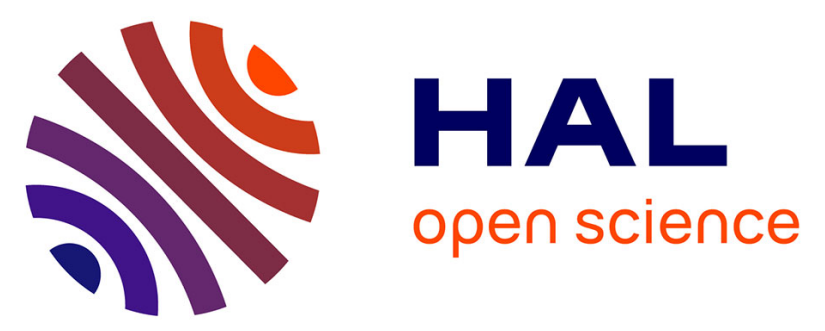

\title{
Effectiveness of a Short Functional Restoration Program for Patients with Chronic Low Back Pain: a cohort study of 193 Patients
}

Davergne Thomas, Bailly Florian, Foltz Violaine, Lambert Anne, Fautrel

Bruno, Gossec Laure

\section{To cite this version:}

Davergne Thomas, Bailly Florian, Foltz Violaine, Lambert Anne, Fautrel Bruno, et al.. Effectiveness of a Short Functional Restoration Program for Patients with Chronic Low Back Pain: a cohort study of 193 Patients. Joint Bone Spine, In press, 87 (6), pp.640-646. 10.1016/j.jbspin.2020.05.011 . hal03183386

\section{HAL Id: hal-03183386 \\ https://hal.science/hal-03183386}

Submitted on 27 Mar 2021

HAL is a multi-disciplinary open access archive for the deposit and dissemination of scientific research documents, whether they are published or not. The documents may come from teaching and research institutions in France or abroad, or from public or private research centers.
L'archive ouverte pluridisciplinaire HAL, est destinée au dépôt et à la diffusion de documents scientifiques de niveau recherche, publiés ou non, émanant des établissements d'enseignement et de recherche français ou étrangers, des laboratoires publics ou privés. 


\section{Effectiveness of a Short Functional Restoration Program for Patients with Chronic Low Back Pain: a cohort study of 193 Patients}

Davergne Thomas $^{1,2}$, Bailly Florian ${ }^{1,2}$, Foltz Violaine ${ }^{2}$, Lambert Anne $^{2}$, Fautrel Bruno ${ }^{1,2}$, Gossec Laure ${ }^{1,2}$

1. Sorbonne Université, INSERM, Institut Pierre Louis d'Épidémiologie et de Santé Publique, (IPLESP), (équipe PEPITES), F75013, Paris, France

2 Pitié Salpêtrière hospital, AP-HP, Rheumatology department, Paris, France

Keywords: Low back pain; functional restoration program; disability

Corresponding author: Davergne Thomas, thomas.davergne@gmail.com, 47-83 Boulevard de l'Hôpital, 75013 Paris.

Word count of full text : 3099

Word count of abstract: 250

Number of references: 30

Figures/Tables: 6 


\section{Abstract}

Background: Functional restoration programs (FRPs) are integrative programs to improve function in chronic low back pain (cLBP). They are costly and time-consuming. The aim was to assess the effectiveness of a condensed FRP (CFRP) for patients with cLBP in professional activity.

Methods: Longitudinal 3 months study of patients with CLBP in one tertiary care hospital, participating in a CFRP over 4 separate days. The primary outcome was the Oswestry Disability Index (ODI). Secondary outcomes included pain, quality of life (EQ5D), patient acceptable symptom state, presenteeism, absenteeism and psychological distress. Outcomes were compared using paired sample Student's t-test or Chi2 between baseline and last follow-up. Logistic regression was used to identify factors associated with better response (improvement of ODI higher than 12.8).

Results: In all, 193 patients were analysed, mean age 44.6 (standard deviation (SD) 10.4) years, mean cLBP duration 9.0 (SD 8.8) years. A small improvement was observed for ODI (mean difference $-5.9,95 \%$ confidence interval: $-7.6,-4.1$ ), as well as most other outcomes. Multivariate analysis showed an association between ODI improvement and higher duration of low back pain (odds ratio for 5 years: $1.41(1.06,1.88))$ and lower baseline back strength (Sorensen, odds ratio for 1 minute: $0.54(0.29,0.99)$ ).

Conclusion: this CFRP showed small effect to improve function, pain and other quality of life, in cLBP. Four-day programs may be an interesting option in cLBP patients still in professional activity for whom a long 1-month FRP is difficultly manageable. Further studies with randomized controlled designs are needed to confirm the benefits.

\section{Introduction}

Low back pain (LBP) is a major problem throughout the world: leading cause of years lived with disability in both developed and developing countries and the sixth cause of overall 
disease burden (disability-adjusted life-years) [1]. The lifetime prevalence of low back pain is up to $84 \%$ [2] with a negative social and psychological impact [3].

LBP has a certain risk of recurrence and can become chronic [4]. Multidisciplinary rehabilitation, also known as functional restoration programs (FRPs), appears to be one of the most effective therapies to improve back pain and decrease disability and long-term work impairment in chronic LBP (cLBP) [4,5] and is recommended by national guidelines [6-8]. Key concepts of these programs are based on a physical component (such as specific exercise modalities) and at least one other element from a biopsychosocial approach (psychological, social, occupational or educational) and are delivered by health professionals from different disciplines [5]. However, time and resources required for full-time FRPs are a limit to their use.

Furthermore, FRPs concern patients with long-term disabling cLBP with a prolonged sick leave and aim to allow patients to get back to work [9]. Such programs are not well adapted for patients still at work, since they require full time participation over several weeks (usually 2-6 weeks), while the number of persons with LBP and still working is very high $[10,11]$. Targeting patients with cLBP in professional activity may be useful since they are at high risk of work consequences.

Thus, a condensed program of the same type as a full-time FRP may be a more feasible alternative for patients with persistent disability who are still at work. Previous studies have shown that such condensed programs have the potential to improve function, prevent sick leave, improve presenteeism and pain and appear to be well accepted [12-15].

The objective was to assess the effectiveness of a CFRP for patients with cLBP in professional activity. 


\section{Patients and Methods}

\section{Study design}

In this observational cohort study, data were prospectively collected in a single tertiary care center in Paris, France. This department provides pluridisciplinary (physicians and health professionals) services for patients with CLBP in an ambulatory setting [9]. Outcomes were measured at baseline, at the end of the 4-week program and at the 3-month follow-up and the main analysis was based on the latest available data (i.e. 3 months when available, else 1 month).

This study was in the context of usual care. No approval was required as stated by the ethics committee in charge or this study (ethical committee Sud-Est VI, Lyon ,Groupement Hospitalier Est, Bâtiment Pinel, 59 Boulevard Pinel, 69500 BRON, FRANCE). Consent was obtained for experimentation with human subjects. This study was reported in accordance with the STrengthening the Reporting of OBservational studies in Epidemiology (STROBE) statement (Supplementary material A) [16].

\section{Population}

Patients included in the program met the following criteria: nonspecific cLBP ( $>3$ months as defined in the European guidelines for the management of chronic [2]), not currently in prolonged sick leave (more than one week), no current indication for surgery (e.g. pain radiating to a precise and entire leg dermatome with neurologic signs [17], fluent in French, and difficulties to maintain daily physical activity due to LBP despite outpatient care including physiotherapy. Nonspecific LBP was defined as LBP not attributable to a recognizable, known specific pathology (e.g., osteoporosis, structural deformity, infection, tumour, fracture, inflammatory disorder, radicular syndrome, or cauda equina syndrome) [4]. Exclusion criteria were specific LBP and medical contraindication to physical exercise. 
Every patient who participated in the CFRP between April 2012 and April 2018 was analysed if the Oswestry Disability Index and lumbar and radicular pain at baseline and at the end of the intervention or 3-month follow-up was available.

\section{Intervention}

The CFRP is a complex multidisciplinary intervention proposed as a usual care, according to different national guidelines, where FRP is defined as intervention that combines and coordinates physical, vocational, and behavioral components and is provided by multiple health care professionals with different clinical backgrounds [6-8]. The program takes place in our department of rheumatology in Pitié-Salpêtrière Hospital, 6 hours per day, 1 day a week, for 4 weeks. Patients are included during consultation or hospitalization and are in groups of 6 maximum per CFRP. The CRFP was developed on the basis of therapeutic patient education programs and physical exercises $[8,18]$. The interdisciplinary team involved and the different components of intervention are detailed in Table 1. A few hours per day are devoted to physical exercises (17\% to $67 \%$ ), led by a physical activity specialist, physiotherapist or yoga teacher which are divided into three periods: warm-up, stretching, and muscle strengthening. Specific exercises adapted to work circumstances (like handling: e.g, lift a weight from the ground) are taught by an occupational therapist. Muscle strengthening is based on isotonic contraction on fitness devices. Patient education is given over on 1 hour per week and focuses on back pain, lumbar ergonomics, cognitive therapy and information on medication. Educational booklets, containing general information about back pain such as possible causes, tips to stay active or treatment, are also given to the patients. Patients were present each day of the program for the same duration (9 am to 4 pm) with a varying duration of lunch break. Although physical activity and exercises were promoted during patient education sessions, no prescription of exercises was made between each session and exercises were not mandatory, or measured. 


\section{Data collection}

The outcomes were collected prospectively in a paper form. The primary outcome was the Oswestry Disability Index, which gives a subjective percentage score of level of function (disability) on a 0 to 100 scale, 100 being the highest disability state [19]. Secondary outcomes included a visual analogue scale of lumbar pain and radicular pain (0-100 scale), EQ-5D-3L for quality of life [20] converted into a global index score with 1 indicating no restriction of quality of life and -1 the worse quality of life possible [21], patient acceptable symptom state where patients reported their satisfaction on state of symptoms by picking "acceptable" or "non-acceptable" [22]. We also collected the validated World Health Organization Health and Work Performance Questionnaire for presenteeism (reflecting the patient's overall performance while at work during the past 4 weeks, score from 0 to 100,100 being the highest level of performance) and absenteeism (proportion of hours lost with regards to the hours expected to work per month, score from 0 to100, 100 indicates the higher amount of absenteeism) [23] and the Hospital Anxiety and Depression scale (HAD) with a probable anxiety or depression disorder corresponding to a score $>11$ [24]. Physical examination assessed Shirado and Sorensen for strength to measure the endurance (in seconds) of the trunk flexor and extensor muscles, Schober test and fingertip-to-floor test for flexibility.

Other variables collected at baseline were age, gender, body mass index, duration of LBP, a measure of stress at work using the Karasek questionnaire (psychological demand, social latitude, social support), professional activity (yes or no) and socio-professional category (high being defined as higher managerial, administrative and professional occupations) [25].

\section{Statistical methods}

Before-after comparison used data at last follow-up (3 months follow-up or at the end of intervention if not available) and was performed using paired sample Student's t-test or Mac 
Nemar's Chi2 test on complete data only. Analyses were also conducted separately with data at end of treatment and with at 3 months for sensitivity analysis (Supplementary material B). Mean differences and standardized mean differences were computed. To interpret the standardized mean differences, the following norms were used: small effect $(<0.3)$, moderate effect $(0.3-0.8)$ or large effect $(>0.8)$ [26]. Changes above the minimal clinically important difference were computed for Oswestry (12.8 out of 100), pain (20 out of 100), anxiety and depression scores (both 1.5) [27-29]. Subgroup analysis was performed to compare effectiveness between patients with high level of symptoms at baseline (Oswestry $>20 / 100$ and pain $>20 / 100$ ) versus low level of symptoms.

The normality of each variable was assessed visually and since this condition was met, parametric tests were used. Factors associated with response, defined as an increase in Oswestry Disability Index higher than the minimal clinically important difference, were analysed using Student, Chi2 and multivariate logistic regression. Explanatory variables in the logistic regression model were entered from a set of a priori variable if statistically associated in univariate analysis $(p<0.2)$, then selected based on missing data and correlation (Supplementary material C). Variables finally entered in the multivariate model were: duration of low back pain, Sorensen (back strength), baseline anxiety (HAD), baseline patient acceptable symptom state, baseline lumbar pain, socio-professional category, Karasek social support and the multivariate analysis concerned 129 patents with full data (i.e. data at 3 months follow-up or at the end of intervention if not available). P values smaller than 0.05 were considered significant. Analyses were carried out using R version 3.5.1.

\section{Results}

\section{Patients}

In all, of the 274 patients who followed the program during the evaluation period, 193 patients were analysed since they had follow-up data (85 patients at the end of the 
intervention and 108 at 3 months, figure 1). The 85 patients who did not return for the visit at 3 months presented the same characteristics at baseline except for Shirado score which was lower (data not shown).

Baseline characteristics are reported in table 2. Mean age was 44.6 (standard deviation (SD) 10.4) years and $76(39 \%)$ were male, mean LBP duration was 9.0 (SD 8.8) years (median = 5.0 years ; minimum $=8.0$ months). The mean body mass index was in overweight values: $26.6(\mathrm{SD} 8.8) \mathrm{kg} / \mathrm{m}^{2}$. Among the $162(84 \%)$ with a paid work, 78 (48\%) were in high socioprofessional category, mean psychological demand was high (>21) and mean social support and social latitude were low ( $<24$ and $<70$ respectively) according to Karasek score. At baseline, mean intensity of lumbar pain was 38.2 (SD 23.4), the mean Oswestry Disability Index was 29.7 (SD 14.0) and symptom state was acceptable for $79(46 \%)$ of patients.

\section{Effectiveness of the CFRP}

Comparisons between baseline and last follow-up (i.e. data at 3 months follow-up or at the end of intervention if not available) showed a small improvement in the Oswestry Disability Index (mean difference $-5.9,95 \%$, confidence interval $(\mathrm{Cl}):-4.1,-7.6)$, as well as lumbar pain, EQ-5D quality of life, patient acceptable symptom state, Shirado and Sorensen, fingertip to floor test, anxiety, depression and absolute presenteeism (Table 3). This improvement was also noted for patients only at one month or 3 months follow-up: Oswestry Disability Index (mean difference $-3.9,95 \%, \mathrm{Cl}:-1.2,-5.6$ at one month and mean difference $-6.8,95 \% \mathrm{Cl}:-4.0,-9.6$ at 3 months follow-up), VAS of lumbar pain (mean difference -5.9 , 95\%, Cl: $-2.2,-9.6$ at one month and mean difference $-6.9,95 \% \mathrm{Cl}:-1.7,-10.1$ at 3 months follow-up) (Supplementary material B). The change was higher than the minimal clinically important difference for 47 (24\%) patients for the Oswestry disability Index, 60 (31\%) for lumbar pain, 80 (44\%) for anxiety and 68 (38\%) for depression. Furthermore, 42 (24\%) changed status positively for the patient acceptable symptom state. Standardised mean differences of quantitative variables (figure 2) indicated higher effect for trunk extensor 
muscles and Oswestry Disability Index ( 0.55 and 0.4 respectively). Before-after comparisons based on data only at the end of the intervention $(n=85)$ or at 3 months follow-up $(n=108)$ showed similar results (Supplementary material B). Subgroup analysis showed a significantly higher improvement in patients with higher symptoms at baseline (mean difference -8.3) than those with lower symptoms at baseline (mean difference -3.2$), 95 \% \mathrm{Cl}$ 8.8, - -1.4.

\section{Variables associated to better response to CFR}

Among the 193 participants, $47(24 \%)$ had a clinically significant improvement of their Oswestry Disability Index at last follow-up and were classified as good response. In univariate analyses, a significant association was observed between good response at last follow-up and baseline characteristics: low functional status or high physical impairment (Oswestry Disability Index: $p<0001$ ), low back strength (Sorensen: $p=0.04$ ), high absolute presenteeism (World Health Organization Health and Work Performance Questionnaire: $p=0.01)$ and substantial anxiety ( $H A D, p=0.03)$. Multivariate analysis showed a significant association between good response and high duration of low back pain (odds ratio of 5 years: $1.41(95 \% \mathrm{Cl}: 1.06,1.88))$ and low baseline back strength according to Sorensen (odds ratio for 1 minute: $0.54(95 \% \mathrm{Cl}: 0.29,0.99))$ (table 4).

Analyses based on data at 3 months follow-up were overall confirmatory (Supplementary material D).

\section{Discussion}

This study explored an innovative condensed program applicable to patients with cLBP without sick leave. It constitutes an interesting alternative easy to implement for patients still working for whom a long FRP requires a long work interruption. Currently, FRPs are being used to improve the outcomes of CLBP, however, they are long, time-consuming and costly 
[6-8]. The option proposed here is a four-days intervention spread over one month, including both physical activity and behavioral components, which is compatible with maintaining professional activity. In this pilot observational study, we were able to demonstrate that the CFRP led to a statistically significant but not clinically significant improvement in the key outcomes of CLBP which are disability and pain, as well as improvements in most of the other outcomes analyzed including work outcomes, psychological status, strength and flexibility, both at the end of intervention and 3 months follow-up. Furthermore, it appeared that patients with the best response to the CFRP were those with a higher duration of low back pain and a lower baseline back-strength at baseline.

At baseline, the Oswestry Disability Index, pain levels and anxiety and depression level were moderate in this young to middle aged population. These levels of pain and disability were lower than those described in previous studies where the Oswestry score is usually around 40 and pain around between 50 and $80[9,12-15,30]$. This difference in level of symptoms could be explained because patients included in this CFRP had chronic but moderately impactful symptoms and were still at work. Thus, it is logical that the symptom level is lower than in patients starting a full time FRP [9]. Surprisingly, the level of lumbar pain (38.2 (23.4)) at baseline was lower that the level of radicular pain (45.5 (19.9)) (Table 2). This result could be explained by the fact that mean radicular pain was calculated for patients with radicular pain only (i.e. $>1$ ).

Comparison between baseline and last follow-up showed a mean difference of 5.9 in the Oswestry Disability Index. This improvement was also noted for patients only at one month (mean difference -3.9) or 3 months follow-up (mean difference -6.8). This significant effect on the Oswestry was of a small magnitude; furthermore only $47(24 \%)$ patients had a clinically relevant improvement of the Oswestry Disability Index. This small effect may be partly explained by the moderate disability at baseline. Subgroup analysis showed a significantly higher improvement in patients with higher symptoms at baseline than those with lower symptoms at baseline. In other studies, larger effects were often observed 
(between 10 and 20 points) [14,30]. However, this effect was observed after an intensive functional therapy with cognitive treatment or after a 2 week program, including cognitive behavioral training, physical activities and education, which was much more time-consuming and resource-consuming than our CRFP $[14,30]$.

Change in levels of pain was of small amplitude (mean difference $-7.7 / 100$ ). This change was lower than previous study $[13,30]$. which could be explained by a less intensive cognitive treatment for pain and lower baseline level of pain.

In this study, CFRP was effective to improve pain, quality of life, patient acceptable symptom state, strength, flexibility, anxiety, depression and presenteeism. Effectiveness on presenteeism is important since a main aim of a CFRP is to improve work outcomes. No significant difference was observed on leg pain and relative absenteeism, probably due to lack of power and small follow-up. Depression did not significantly change, but levels at baseline were low.

A significant association was observed between response and higher duration of low back pain and lower baseline back strength. This could be explained because patients with higher duration of low back pain and lower back strength may have also the worst state of function, though this should be explored further.

This study has strengths and weaknesses. The design was a cohort study which does not control for other sources of effects (such as contextual factors) but allows to reflect clinical practice [31]. The results of this study should be confirmed by randomized controlled trials. However, the positive effect observed across different outcomes is obtained from a large population $(\mathrm{N}=193)$ and pleads in favor of the efficacy of the CFRP. In terms of population, the CFRP is mostly indicated for patients currently in professional activity. However, $16 \%$ of patients were included even though they were not currently working, mostly because they were on short-term sick leave. The outcomes chosen for the study reflect both physical, psychological and professional activity. It could have been useful to analyse factors 
associated with absenteeism. However, because this variable was not available in all the patients, we analysed the Oswestry disability index as primary outcome: this is a well validated and widely used outcome in LBP [19]. We did not collected the number of recurrences features of chronical pain states of an single episode to characterise chronicity. However, since mean duration was 9.0 year, we have classified patients as "chronic". The follow-up chosen for this study (3 months) is short to evaluate the impact of an intervention with an average duration of the disease of 9 years. A longer follow-up should be considered in a more in-depth study. Finally, a high lack of follow up at the 3 month time point was observed (36\%). This could be explained by a high rate of patient still working who had difficulties to reach the hospital during a working day just for an assessment. Another explanation may be that there is no need to return to the hospital due to better health. This drop out ratio didn't allow to carry out an intent to treat analysis. However, no differences were found when comparing their characteristics (except for strength at baseline) and the efficacy of the CFRP was similar at the end of intervention and 3 months follow-up.

In conclusion, a 4-day interventions for chronic LBP in professional activity showed a small effect in improving physical function and avoiding professional consequences of cLBP while maximising feasibility. These results, if confirmed by other studies, may encourage other centres to implement a condensed functional program, and may help to choose who to orient towards this CFRP. Further studies are needed to assess the benefits on work outcomes such as sick leave with longer follow-up.

Disclosures: Davergne Thomas, None; Bailly Florian, None, Foltz Violaine, None, Lambert Anne, None, Fautrel Bruno, None, Gossec Laure, None.

Funding: This usual care study was performed in Assistance Public des Hôpitaux de Paris (AP-HP). Thomas Davergne received funding from Groupe d'Etudes et de Recherche sur les Pathologies de l'Appareil Locomoteur (GERPAL). 
Author contributions: Davergne Thomas: Conceptualization; Data curation; Formal analysis; Funding acquisition; Investigation; Methodology; Project administration; Supervision; Validation; Visualization; Writing - original draft; Bailly Florian : Data curation; Formal analysis; Methodology; Supervision; Validation; Visualization; Writing - review \& editing; Foltz Violaine : Supervision; Writing - review \& editing; Lambert Anne : Data curation; Funding acquisition; Investigation; Writing - review \& editing; Fautrel Bruno : Supervision; Writing - review \& editing; Gossec Laure : Data curation; Formal analysis; Funding acquisition; Investigation; Methodology; Project administration; Supervision; Validation; Visualization; Roles/Writing - original draft; Writing - review \& editing. 


\section{References}

[1] GBD 2017 Disease and Injury Incidence and Prevalence Collaborators. Global, regional, and national incidence, prevalence, and years lived with disability for 354 diseases and injuries for 195 countries and territories, 1990-2017: a systematic analysis for the Global Burden of Disease Study 2017. Lancet 2018;392:1789-858. https://doi.org/10.1016/S0140-6736(18)32279-7.

[2] Airaksinen O, Brox JI, Cedraschi C, Hildebrandt J, Klaber-Moffett J, Kovacs F, et al. Chapter 4 European guidelines for the management of chronic nonspecific low back pain. Eur Spine $J$ 2006;15:s192-300. https://doi.org/10.1007/s00586-006-1072-1.

[3] Bailly F, Foltz V, Rozenberg S, Fautrel B, Gossec L. The impact of chronic low back pain is partly related to loss of social role: A qualitative study. Joint Bone Spine 2015;82:437-41. https://doi.org/10.1016/j.jbspin.2015.02.019.

[4] Maher C, Underwood M, Buchbinder R. Non-specific low back pain. The Lancet 2017;389:736-47. https://doi.org/10.1016/S0140-6736(16)30970-9.

[5] Kamper SJ, Apeldoorn AT, Chiarotto A, Smeets RJEM, Ostelo RWJG, Guzman J, et al. Multidisciplinary biopsychosocial rehabilitation for chronic low back pain. Cochrane Database Syst Rev 2014:CD000963. https://doi.org/10.1002/14651858.CD000963.pub3.

[6] Chou R, Huffman LH, American Pain Society, American College of Physicians. Nonpharmacologic therapies for acute and chronic low back pain: a review of the evidence for an American Pain Society/American College of Physicians clinical practice guideline. Ann Intern Med 2007; 147:492-504.

[7] National Institute for Health and Care Excellence. Non-specific low back pain and sciatica: management. NICE guideline: short version. Draft for consultation, March 2016. 2019.

[8] KCE. Low back pain and radicular pain: assessment and management 2019.

[9] Poulain C, Kernéis S, Rozenberg S, Fautrel B, Bourgeois P, Foltz V. Long-term return to work after a functional restoration program for chronic low-back pain patients: a prospective study. Eur Spine J 2010;19:1153-61. https://doi.org/10.1007/s00586-010-1361-6.

[10] Andersson GB. Epidemiological features of chronic low-back pain. The Lancet 1999;354:581-5. https://doi.org/10.1016/S0140-6736(99)01312-4.

[11] Salathé CR, Melloh M, Crawford R, Scherrer S, Boos N, Elfering A. Treatment Efficacy, Clinical Utility, and Cost-Effectiveness of Multidisciplinary Biopsychosocial Rehabilitation Treatments for Persistent Low Back Pain: A Systematic Review. Global Spine Journal 2018:2192568218765483. https://doi.org/10.1177/2192568218765483.

[12] Demoulin C, Grosdent S, Capron L, Tomasella M, Somville P-R, Crielaard J-M, et al. Effectiveness of a semi-intensive multidisciplinary outpatient rehabilitation program in chronic low back pain. Joint Bone Spine 2010;77:58-63. https://doi.org/10.1016/j.jbspin.2009.11.003.

[13] Albaladejo C, Kovacs FM, Royuela A, del Pino R, Zamora J, Spanish Back Pain Research Network. The efficacy of a short education program and a short physiotherapy program for treating low back pain in primary care: a cluster randomized trial. Spine 2010;35:483-96. https://doi.org/10.1097/BRS.0b013e3181b9c9a7.

[14] van Hooff ML, van der Merwe JD, O'Dowd J, Pavlov PW, Spruit M, de Kleuver M, et al. Daily functioning and self-management in patients with chronic low back pain after an intensive cognitive behavioral programme for pain management. Eur Spine J 2010;19:1517-26. https://doi.org/10.1007/s00586-010-1435-5.

[15] Garofoli R, Boisson M, Segretin F, Linières J, Gérard C, Moreau S, et al. Feasibility of a short multidisciplinary education and exercise therapy program for patients with non-specific low back pain: A 3-month retrospective open pilot study. Annals of Physical and Rehabilitation Medicine 
2019. https://doi.org/10.1016/j.rehab.2019.05.005.

[16] von Elm E, Altman DG, Egger M, Pocock SJ, Gøtzsche PC, Vandenbroucke JP. The Strengthening the Reporting of Observational Studies in Epidemiology (STROBE) statement: guidelines for reporting observational studies. Journal of Clinical Epidemiology 2008;61:344-9. https://doi.org/10.1016/j.jclinepi.2007.11.008.

[17] Abenhaim L, Rossignol M, Valat J-P, Nordin M, Avouac B, Blotman F, et al. The Role of Activity in the Therapeutic Management of Back Pain: Report of the International Paris Task Force on Back Pain. Spine 2000;25:1S.

[18] Desthieux C, Dadoun S, Foltz V, Rozenberg S, Roure F, Fautrel B, et al. Functional restoration programs for chronic low back pain patients are not just a fitness class - change in muscle mass assessed through DXA in 95 patients: a monocentric longitudinal study. Osteoarthritis and Cartilage 2014;22:S438-9. https://doi.org/10.1016/j.joca.2014.02.829.

[19] Fairbank JCT, Pynsent PB. The Oswestry Disability Index. Spine 2000;25:2940.

[20] EuroQol Group. EuroQol--a new facility for the measurement of health-related quality of life. Health Policy 1990;16:199-208.

[21] Szende A, Oppe M, Devlin N, editors. EQ-5D Value Sets: Inventory, Comparative Review and User Guide. Springer Netherlands; 2007.

[22] Tubach F, Ravaud P, Martin-Mola E, Awada H, Bellamy N, Bombardier C, et al. Minimum clinically important improvement and patient acceptable symptom state in pain and function in rheumatoid arthritis, ankylosing spondylitis, chronic back pain, hand osteoarthritis, and hip and knee osteoarthritis: Results from a prospective multinational study. Arthritis Care Res (Hoboken) 2012;64:1699-707. https://doi.org/10.1002/acr.21747.

[23] Kessler RC, Ames M, Hymel PA, Loeppke R, McKenas DK, Richling DE, et al. Using the World Health Organization Health and Work Performance Questionnaire (HPQ) to evaluate the indirect workplace costs of illness. J Occup Environ Med 2004;46:S23-37.

[24] Zigmond AS, Snaith RP. The hospital anxiety and depression scale. Acta Psychiatr Scand 1983;67:361-70.

[25] Niedhammer I, Ganem V, Gendrey L, David S, Degioanni S. Propriétés psychométriques de la version française des échelles de la demande psychologique, de la latitude décisionnelle et du soutien social du « Job Content Questionnaire » de Karasek : résultats de l'enquête nationale SUMER, Summary. Santé Publique 2006;18:413-27.

[26] Cohen J. Statistical Power Analysis for the Behavioral Sciences. 2 edition. Hillsdale, N.J: Routledge; 1988.

[27] Johnsen LG, Hellum C, Nygaard ØP, Storheim K, Brox JI, Rossvoll I, et al. Comparison of the SF6D, the EQ5D, and the oswestry disability index in patients with chronic low back pain and degenerative disc disease. BMC Musculoskeletal Disorders 2013;14:148.

https://doi.org/10.1186/1471-2474-14-148.

[28] Ostelo RWJG, de Vet HCW. Clinically important outcomes in low back pain. Best Practice \& Research Clinical Rheumatology 2005;19:593-607. https://doi.org/10.1016/j.berh.2005.03.003.

[29] Puhan MA, Frey M, Büchi S, Schünemann HJ. The minimal important difference of the hospital anxiety and depression scale in patients with chronic obstructive pulmonary disease. Health Qual Life Outcomes 2008;6:46. https://doi.org/10.1186/1477-7525-6-46.

[30] O'Sullivan K, Dankaerts W, O’Sullivan L, O'Sullivan PB. Cognitive Functional Therapy for Disabling Nonspecific Chronic Low Back Pain: Multiple Case-Cohort Study. Phys Ther 2015;95:1478-88. https://doi.org/10.2522/ptj.20140406.

[31] Gamble J-M. An Introduction to the Fundamentals of Cohort and Case-Control Studies. Can J Hosp Pharm 2014;67:366-72. 


\section{Figure:}

Figure 1: Flow chart of patients with chronic low back pain participating in a condensed functional restoration program between April 2012 and April 2018

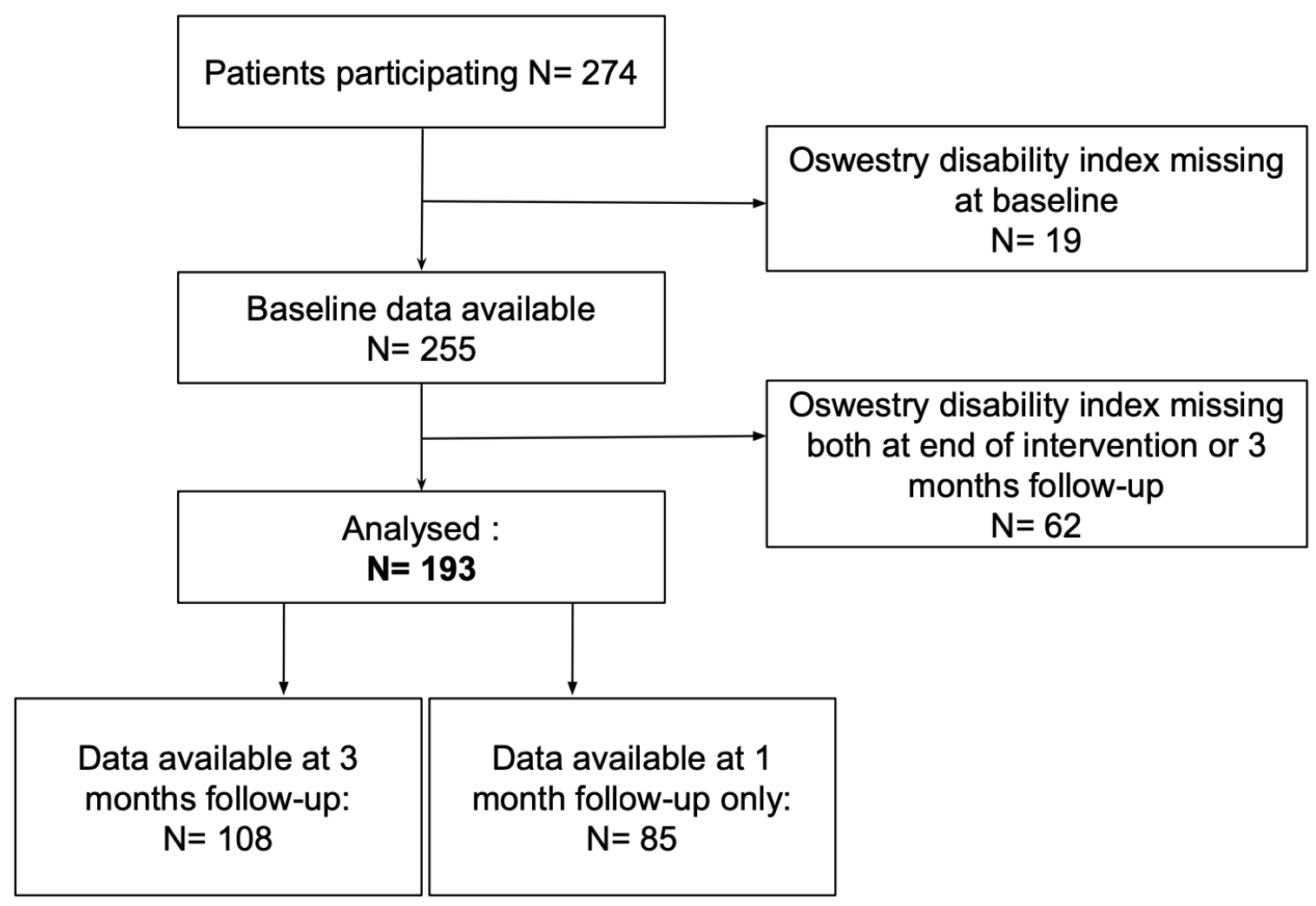


Figure 2: Standardised mean differences of quantitative variables measured before and after the CFRP for patients with cLBP.

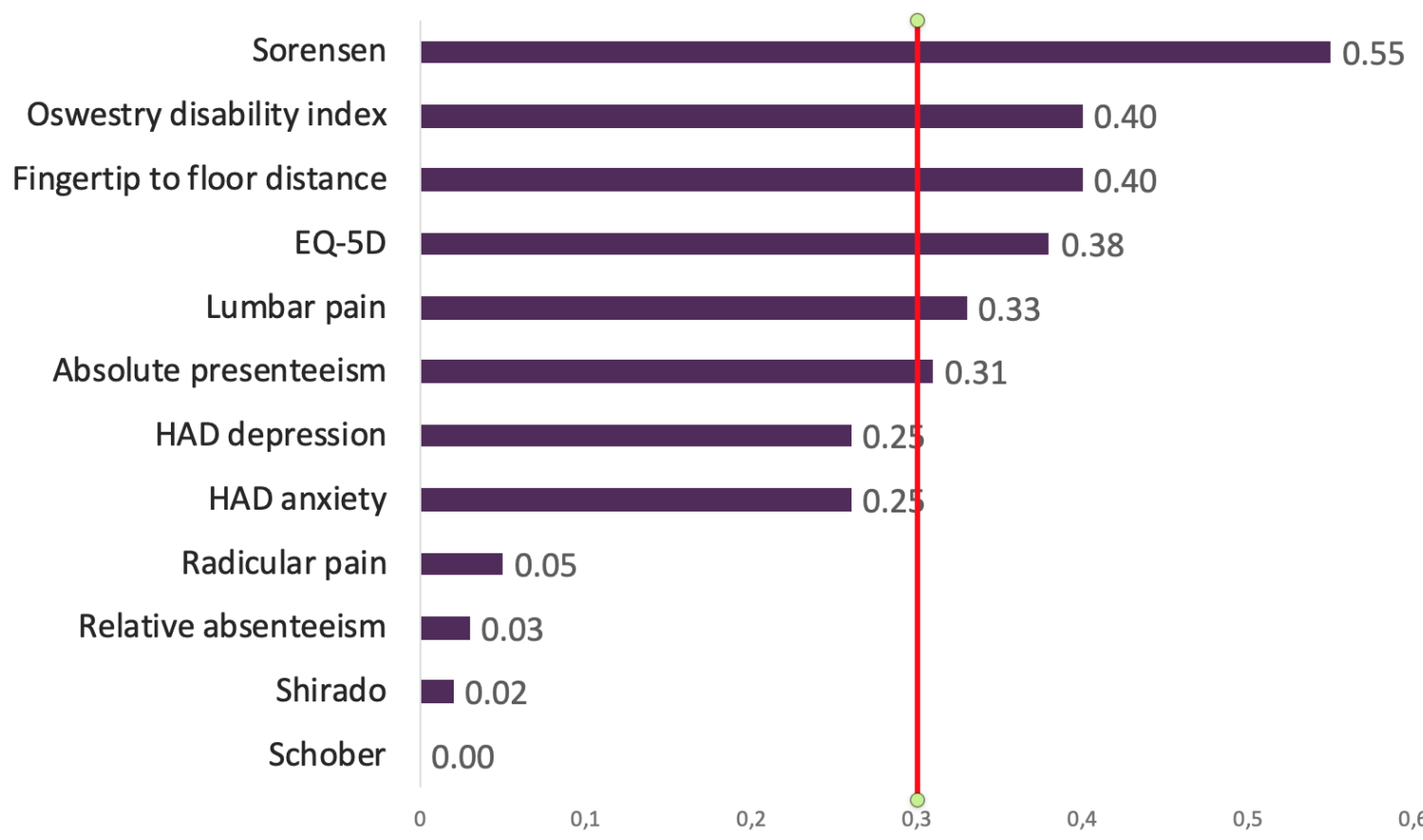

Footnote: $X$ axis: Standardized mean difference, $Y$ axis: outcomes. The vertical bar represents a standardized mean difference of 0.3 , which is the usual cutoff between low and moderate effects.

HAD: Hospital Anxiety and Depression scale. 
Table 1: Description of the condensed functional restoration program for patient with chronic low back pain.

\begin{tabular}{|l|l|l|l|}
\hline & Activity & Duration & $\begin{array}{l}\text { Week } \\
\text { number }\end{array}$ \\
\hline $\begin{array}{l}\text { Physiotherapist trained in } \\
\text { therapeutic education of the patient }\end{array}$ & Assessment & $2 \mathrm{~h}$ & 1,4 \\
\hline Physical activity specialist & Stretching and Fitness & $2 \mathrm{~h}$ & 1 \\
\hline Pain Physician & Neurophysiology of pain information & $1.5 \mathrm{~h}$ & 1,2 \\
\hline Physiotherapist & $\begin{array}{l}\text { Fitness, Proprioception, Sitting gymnastics } \\
\text { and Gym ball }\end{array}$ & $2 \mathrm{~h}$ & 2,3 \\
\hline Occupational therapist & Lumbar ergonomy (theory and practice) & $1 \mathrm{~h}$ & 2,3 \\
\hline Yoga teacher & Yoga lesson & $1 \mathrm{~h}$ & 2,4 \\
\hline $\begin{array}{l}\text { Physiotherapist trained in cognitive- } \\
\text { behavioural therapy }\end{array}$ & Cognitive-behavioural therapy & $1.5 \mathrm{~h}$ & 3 \\
\hline Nurse & Information on medication & $1.5 \mathrm{~h}$ & 3 \\
\hline $\begin{array}{l}\text { Occupational therapist and } \\
\text { Adapted physical activity specialist }\end{array}$ & Sport and sexuality workshop & $1.5 \mathrm{~h}$ & 4 \\
\hline Dietitian & Lifestyle workshop & $1.25 \mathrm{~h}$ & 4 \\
\hline
\end{tabular}


Table 2: Baseline characteristics of 193 patients with chronic low back pain attending a condensed functional restoration program

\begin{tabular}{|l|l|}
\hline Characteristics & Values (N=193) \\
\hline Age, years, mean (SD), range & $44.6(10.4)$ \\
\hline Gender, male, N (\%) & $76(39.0)$ \\
\hline LBP duration, years, mean (SD) & $9.0(8.8)$ \\
\hline Professional activity: Yes, N (\%) & $162(84.0)$ \\
\hline Body mass index (kg·m-2), mean (SD) & $26.4(8.8)$ \\
\hline Karasek psychological demand (9-36), mean (SD)* & $23.9(5.1)$ \\
\hline Karasek social latitude, mean (SD)* & $67.8(13.9)$ \\
\hline Karasek social support, mean (SD) ${ }^{*}$ & $21.0(6.2)$ \\
\hline Socio-professional category ${ }^{£},(\mathrm{high}) \mathrm{N}(\%)^{*}$ & $78(48.0)$ \\
\hline Oswestry Disability Index, mean (SD) & $29.7(14.0)$ \\
\hline Lumbar pain (0-100), mean (SD) & $38.2(23.4)$ \\
\hline Radicular pain, yes, N (\%) & $96(49.7)$ \\
\hline Radicular pain (0-100), mean (SD) & $45.5(19.9)$ \\
\hline Patient acceptable symptom state, N (\%) & $79(46.0)$ \\
\hline
\end{tabular}

SD: standard deviation

* Karasek scores and socio-professional category were analysed among workers only, $\mathrm{n}=162$

${ }^{£}$ High socio-professional category was being defined as higher managerial, administrative and professional occupations

$\$$ Mean radicular pain calculated on patients with radicular pain, $n=96$ 
Table 3: Effectiveness of a condensed functional restoration program for patients with chronic low back pain.

\begin{tabular}{|c|c|c|c|c|c|c|c|c|}
\hline \multirow[b]{2}{*}{ Outcome } & \multicolumn{4}{|c|}{ Whole cohort $(n=193)$} & \multicolumn{4}{|c|}{ Patients at 3 months only $(n=108)$} \\
\hline & $\begin{array}{l}\text { Baseline } \\
\text { value }\end{array}$ & $\begin{array}{c}\text { Follow- } \\
\text { up } \\
\text { Value }\end{array}$ & p-value & $\begin{array}{c}\text { Mean } \\
\text { difference } \\
(95 \% \mathrm{Cl})\end{array}$ & $\begin{array}{l}\text { Baseline } \\
\text { value }\end{array}$ & $\begin{array}{l}\text { Follow- } \\
\text { up } \\
\text { Value }\end{array}$ & p-value & $\begin{array}{c}\text { Mean } \\
\text { difference } \\
(95 \% \mathrm{Cl})\end{array}$ \\
\hline $\begin{array}{l}\text { Oswestry disability index } \\
(0-100) \text {, mean (SD) }\end{array}$ & $\begin{array}{l}29.7 \\
(14.1)\end{array}$ & $\begin{array}{c}23.8 \\
(15.1)\end{array}$ & $<0.0001$ & $5.9(1.9)$ & $30.4(14)$ & $\begin{array}{l}23.6 \\
(16.1)\end{array}$ & $<0.0001$ & $6.8(2.8)$ \\
\hline $\begin{array}{l}\text { Lumbar pain }(0-100) \text {, mean } \\
\text { (SD) }\end{array}$ & $\begin{array}{c}38.9 \\
(23.3)\end{array}$ & $\begin{array}{l}30.8 \\
(25.9)\end{array}$ & $<0.0001$ & $7.7(3.8)$ & $\begin{array}{l}38.0 \\
(31.0)\end{array}$ & $\begin{array}{c}30 \\
(27.7)\end{array}$ & $<0.01$ & $6.9(5.2)$ \\
\hline $\begin{array}{l}\text { Radicular pain }(0-100) \text {, } \\
\text { mean }(S D)^{*}\end{array}$ & $45(20)$ & $46(23)$ & 0.51 & $2(6.4)$ & $\begin{array}{c}20.6 \\
(25.6)\end{array}$ & $\begin{array}{c}18.4 \\
(26.6)\end{array}$ & 0.45 & $2.2(8.8)$ \\
\hline $\begin{array}{l}\text { EQ-5D }(-0.53-1), \text { mean } \\
\text { (SD) }\end{array}$ & $\begin{array}{c}0.53 \\
(0.26)\end{array}$ & $\begin{array}{c}0.65 \\
(0.26)\end{array}$ & $<0.0001$ & $0.11(0.05)$ & $\begin{array}{c}0.52 \\
(0.27)\end{array}$ & $\begin{array}{l}0.56 \\
(0.31)\end{array}$ & 0.04 & $-0.07(0.1)$ \\
\hline PASS, N (\%) & $79(46)$ & $120(69)$ & $<0.0001$ & - & $49(43)$ & $84(71)$ & $<0.0001$ & - \\
\hline $\begin{array}{l}\text { Absolute presenteeism (0- } \\
\text { 100), mean (SD) }\end{array}$ & $65(20)$ & $71(19)$ & $<0.01$ & $4.7(3.0)$ & $65(20)$ & $68(23)$ & 0.02 & $5.3(4.5)$ \\
\hline $\begin{array}{l}\text { Relative Absenteeism (0- } \\
\text { 100), mean (SD) }\end{array}$ & $14(51)$ & $15(34)$ & 0.99 & $0.00(0.10)$ & $15(61)$ & $24(41)$ & 0.49 & $5(0.1)$ \\
\hline $\begin{array}{l}\text { Shirado (second), mean } \\
\text { (SD) }\end{array}$ & $94(70)$ & $109(70)$ & $<0.0001$ & $15(7.0)$ & $103(75)$ & $117(55)$ & $<0.01$ & $14.1(10.8)$ \\
\hline $\begin{array}{l}\text { Sorensen (second), mean } \\
\text { (SD) }\end{array}$ & $66(54)$ & $95(58)$ & $<0.0001$ & $29(8.3)$ & $73(59)$ & $109(55)$ & $<0.0001$ & $33.1(12.0)$ \\
\hline $\begin{array}{l}\text { Schober test }(\mathrm{cm}) \text {, mean } \\
\text { (SD) }\end{array}$ & $6(3)$ & $6(3)$ & 0.38 & $0(0.4)$ & $6(3)$ & $6(2)$ & 0.85 & $0(0.4)$ \\
\hline $\begin{array}{l}\text { fingertip to floor test }(\mathrm{cm}) \text {, } \\
\text { mean (SD) }\end{array}$ & $20(16)$ & $15(14)$ & $<0.0001$ & $5(1)$ & $19(16)$ & $14(13)$ & $<0.0001$ & $5.0(1.7)$ \\
\hline HAD anxiety, mean (SD) & $9.0(4.0)$ & $7.9(3.8)$ & $<0.0001$ & $1.5(0.4)$ & $9.1(4.0)$ & $7.9(3.9)$ & $<0.0001$ & $1.6(0.6)$ \\
\hline $\begin{array}{l}\text { HAD anxiety, score }>11, N \\
(\%)\end{array}$ & $48(26)$ & $29(15)$ & $<0.0001$ & - & $29(24)$ & $20(17)$ & 0.02 & - \\
\hline $\begin{array}{l}\text { HAD depression, mean } \\
\text { (SD) }\end{array}$ & $6.1(4.0)$ & $5.1(3.7)$ & $<0.0001$ & $1.2(0.4)$ & $6.4(4.1)$ & $5.4(3.9)$ & $<0.0001$ & $1.5(0.6)$ \\
\hline $\begin{array}{l}\text { HAD depression, score } \\
>11, N(\%)\end{array}$ & $14(8)$ & $7(4)$ & 0.07 & 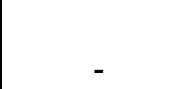 & $12(10)$ & $8(6)$ & 0.24 & - \\
\hline
\end{tabular}

SD: standard deviation ; VAS: visual analogue scale ; HAD: Hospital Anxiety and Depression scale ; *Radicular pain was calculated for patients with radicular pain, $\mathrm{n}=96$

PASS: Patient acceptable symptom state; $\mathrm{SD}=$ Standard deviation; $95 \% \mathrm{Cl}=95 \%$ confident interval

Data were available for more than $90 \%$ of the patients except for PASS (missing in 11\%), absolute presenteeism (missing in $15 \%$ ), relative absenteeism (missing in $20 \%$ ), and EQ-5D (missing in 48\%). 
Table 4: Factors associated to response to the CFRP in 193 patients at last follow-up: Univariate and multivariate logistic regression.

\begin{tabular}{|l|l|l|l|}
\hline Variable & $\begin{array}{l}\text { Univariate } \\
\text { analysis } \\
\text { (P value) }\end{array}$ & Odds Ratio (95\%Cl) & P value \\
\hline $\begin{array}{l}\text { Duration of low back pain, for 5 } \\
\text { years }\end{array}$ & 0.18 & $1.41(1.06,1.88)$ & 0.02 \\
\hline $\begin{array}{l}\text { Sorensen (back strength), for 1 } \\
\text { minute }\end{array}$ & 0.03 & $0.54(0.29,0.99)$ & 0.05 \\
\hline Baseline anxiety (HAD) & 0.04 & $1.09(0.97,1.22)$ & 0.15 \\
\hline $\begin{array}{l}\text { Baseline Patient acceptable } \\
\text { symptom state }\end{array}$ & 0.18 & $0.75(0.3,1.91)$ & 0.55 \\
\hline Baseline lumbar pain & 0.24 & $0.99(0.97,1.01)$ & 0.86 \\
\hline Socio-professional category & 0.01 & $0.73(0.31,1.76)$ & 0.49 \\
\hline Karasek social support & 0.27 & $1.01(0.93,1.08)$ & 0.81 \\
\hline
\end{tabular}

$\mathrm{Cl}$ : Confidence interval

HAD: Hospital Anxiety and Depression scale 